Danilo Dorović

Tedex doo, the consultancy enterprise

\title{
The Hierarchy of Segment Reports
}

UDC:005.912

005.551

DOI: 10.7595/management.fon.2015.0013

\begin{abstract}
The article presents an attempt to find the connection between reports created for managers responsible for different business segments. With this purpose, the hierarchy of the business reporting segments is proposed. This can lead to better understanding of the expenses under common responsibility of more than one manager since these expenses should be in more than one report. The structure of cost defined per business segment hierarchy with the aim of new, unusual but relevant cost structure for management can be established. Both could potentially bring new information benefits for management in the context of profit reporting.
\end{abstract}

Keywords: business segments, hierarchy, activity based costing

\section{Introduction}

Management accounting follows the organizational structure of the company through the concept of responsibility accounting. "A responsibility center is an organizational unit for which a manager is made responsible." (Atkinson et al., 2007, p. 581) It is simply natural to create reports on achieved results of a manager's organizational unit.

The organizational hierarchy, departments and units have the task to successfully implement a defined strategy of the company. It is quite usual that an individual manager, wherever his organizational unit is in the organizational hierarchy, is responsible for the fulfillment of the strategy to a certain extent. The manager is, in simple words, responsible for a certain part of the business.

Segment reports are usually created for different areas of responsibility for each manager - for an individual product or groups of products, for an individual customer or groups of customers, for an individual distribution channel or types of distribution channels, for brands or umbrella brands, for individual market segments or national markets, or, finally, for strategic business units.

The aim of the paper is to propose how these reports for different areas of responsibility of different managers can be structured following the logic of enterprise's strategy hierarchy. In this manner, instead of having separated loosely connected reports the management reports can be structured properly and logically!

If the segment reports created for individual parts of the business could be properly hierarchically connected, it would be possible to track how the result on individual reporting segment influences the results of other segments bellow/above it and of the company in general. Segment reports should be logically interconnected if this goal is to be achieved.

It is also important to emphasize that for some business segments there is no directly responsible management! For example, the marketing function can be shaped per products, customers, brands, channels, markets, market segments, etc. In some cases, the matrix organization will be implemented for product and customer, brand and channels, etc. (Kotler et al., 2009, pp. 773-778) However, usually just two elements can be included in the matrix organization. For example, if customers and brands are included, channels or markets, even market segments are not monitored in the business segment reports. It is reasonable to claim that even if business segments do not have directly responsible managers, they should be somehow monitored. Since results per some segments are not regularly monitored, some developments can surprise the management. Ultimately, responsibility for these business segments that are not under direct supervision of 
the lower level manager will be the responsibility of the top level management. They will need reports that show the achieved results in these "omitted" segments since their responsibility is general.

The danger that some segments can be omitted is partly due to fact that there is no proper hierarchy of segments that is logically connected into the management and management accounting theory. If the hierarchy were known, it would be easy to understand which segments are omitted.

\section{The Previous Attempt for Creation of Hierarchy of Segments in Management Reporting}

Originally, the issue was implicitly introduced by Kotler in one of his books named Marketing management. He identified 90 types of demand measurements per several relevant dimensions. The first is the product level with its sublevels: product itself, class of products, product line, products of the company and products of the industry. The second is the territory with following sublevels: individual customer, territory, region, the USA and the world. The third is the time: short-term, middle-term and long-term. By multiplying the 6 sublevels for the product with 5 sublevels for customers and 3 for time, the author came to a conclusion that there are 90 types of demand measurements. (Kotler, 1972, p. 193) The implicit question is how the reports for all the product levels and all the customer levels are interconnected? The managers should receive the reports per each sublevel, so that they can understand and improve their results per each demand type. But the product results are interconnected with sale per territory, region, national state or individual customers. The vice versa can be also claimed, the results of individual product, product line, etc. are connected with sales per customer, territory, region, national state... So, they are interdependent - but how precisely?

Barrett also identified the problem from the point of data generation and defined the following elements: area, customer type, product, level of service. He showed sales area as the bases, followed by cutomer type, product and level of service. However, he did not try to establish a firm hierarchy between these reporting elements. He just showed that there is interdependency that should be solved during the report shaping. (Barrett, 1980, p. 143) R. Wilson emphasized the previous attempts from other authors to establish the level of segments, but mostly used Barrett's work as an illustration attempt for the issue itself in two of his works. (Wilson, 1999, pp. 41-42; Wilson and Gilligan, 2005, pp. 79-80) Wilson did not try to propose a hierarchy as a potential solution.

$\mathrm{K}$. Ward, as one of the most important establishers of strategic management accounting, showed a type of potential reporting matrix as report of profitability analyses for products and customers. But then he claimed that this report cannot be created! It would show the profitability of customers as dependent on products or profitability of products dependent on customers, but costs cannot be totally separated in a manner which makes it possible for them to be separated per individual customer and product simultaneously. For example, the delivery terms expense is influenced by customer and not by product. Or, expense of production preparation is not possible to be properly allocated by the following cause-effect relation to the customers. (Ward, 1993, pp. 68-69) In this manner, he also introduced the issue of ABC cost hierarchy as one of the reasons for the low possibility of interconnecting the different reporting segments.

Per all previous authors products, customers, geographical areas are specific segments of the business for which the reports should be created. However, it can be easily argued that reporting segments should also include the distributors, brands, market segments, national markets as well as previously mentioned different groups of customers (per territory, age, sex, education, purchasing habits...) and strategic business units the result for which is influenced by all the previous elements. It seems that a valid proposal for the issue of segment reports hierarchy demands that more reporting elements should be explicitly included.

In approaches that can be found in literature, the level of service, different types of customers or customers in a specific area are showed as segments. Still, there is no cohesive idea how the segments should be hierarchically connected, just that they are connected. 


\section{Levels of Strategy and Revenue Generation as Core Ideas for Defining the Hierarchy of Segments}

There are two ideas how the business segment hierarchy for reporting can be established.

The first is that hierarchy inside the strategy can be used to determine the hierarchy of segments. If this can be determined, it will be possible to understand how the fulfillment of the strategy in one segment influences the results of other segments and the overall result of the company.

There are three levels of the strategy: the corporate strategy, the competitive strategy and the functional strategies. (Grant, 1992, pp. 10, 20-21) The corporate strategy defines the business areas or industries, the competitive strategy defines the competitive advantage, while functional strategies have individual roles in creating a competitive advantage.

In modern times the marketing function, due to effect known as "lack of customers," has assumed an integrative role in the business. Due to this, most segments will be determined in their areas of expertise or will be connected with marketing in some manner. Marketing works with products, goods or services, customers, customer types, market segments, markets, brands, distribution channels. For the purpose of this article, all the above mentioned will be defined as elements of the marketing strategy. The marketing strategy, as a functional level strategy, usually covers the stated areas as ones under its exclusive or partial responsibility.

A marketing plan is usually defined per one or more of these elements that the marketing strategy is closely connected with. That is, targets and activities in the marketing plan are closely connected with products, markets, customers, brands, channels. It could be reasonable to assume that the marketing and financial results per each element should be monitored and management accounting reports presented per these elements. There is usually a marketing manager responsible for some of these elements.

The value chain (Porter, 1990, p. 41) defines the activities that create the value for the final customer. The activities will create the benefits relevant for customers on the target markets. At the same time, these benefits should be acceptable for customers when compared with competitors. Only if this is the case, can the expenses for used resources be lower than the price charged for the final product.

If the hierarchy of segments is determined, these activities can be properly allocated to each business segment and the value chain will have its activity expenses broken per segments of business. When having in mind that each activity creates some value, the values generated per reporting segments could be also tracked.

Besides the strategy as a tool for creating the hierarchy, the manner in which the revenues are logically generated can be used as the second principle for defining the hierarchy. For example, products are sold to customers. Due to this, the product cannot be higher than the customer in hierarchy. Products are sold to customers not the opposite, leading to a conclusion that the product is a more basic business segment. The creation of a product or a service demands the expenses. Selling the product to the customer will also mean new expenses connected with customers such as exposure in the shop or promotional effort. These are customer specific and not product specific expenses. Since the product is sold to the customers, it leads to a conclusion that the product is a more basic element in the hierarchy. Considering the introduced principles of way the revenues are generated and three levels of the strategy, the proposal of the segment hierarchy can be introduced.

\section{The Hierarchy of Segments in Business}

At the top of the segment pyramid should be the company itself. Its overall result is based on the results of business areas or industries that the company has chosen to operate. In the following Figure, the proposed hierarchy of business segments is presented. 


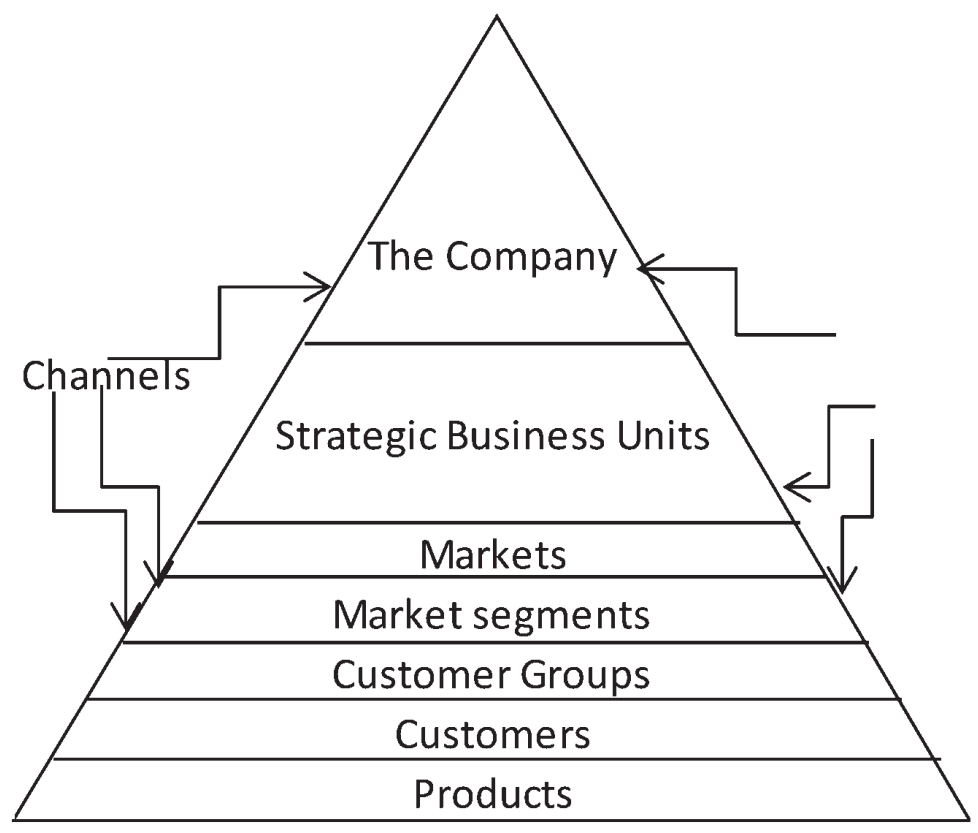

Figure 1: The proposed hierarchy of the business segments

For large companies, it is usual that a division or a strategic business unit operates at a corporate strategy level. The corporate strategy determines the industries in which a SBU of the company will operate. However, further explanation will be continued from the bottom side of the pyramid as more explanatory. The results achieved on these lower segments are creating the result of the strategic business unit or division.

The product is at the core of the competitive advantage of the company. It is the holder of the essential benefits for the consumer. It is the object of costs for creation of these benefits. The production activities that generate product benefits for customers are created on this business segment. Still, the creation of the benefits will not end here.

The company will further have to create the benefits for the customer. Benefits connected with the customer level are delivery to the customer, education as to how to use the product or warranty, etc. All are connected with the activities on the customer level.

In marketing, customers are organized into customer groups. The products are sold to customers that belong to a customer group. In a way, the product transfers its profit to the customer and the customer group level. This is why the product is at the bottom of the pyramid. The marketing department will search for different customer characteristics for which specific customer value can be provided. It will search for a customer whose behavior is more profitable for the company. This is still not the market segment level. The customer groups are parts inside the marketing segment. For example, the company targets the people that like to go to hypermarkets for their monthly purchases. This is the targeted market segment. However, the buyers can be grouped in males or females. Another grouping could be per age or geographic region. Having separate profit contribution report for each of these groups can be beneficial for managers.

Market segments are at the heart of marketing strategy. Defining which market segments are more or less profitable would mean knowing whether the marketing strategy is properly defined and/or whether its implementation is proper. Since the customers organized in the marketing segments are the basic marketing strategy choice, knowing the results of the work on the marketing segment - financial as well as nonfinancial - is at the core of the business segment reporting for marketing.

The contribution to profit originally created by the production activities is further decreased in higher level segments that are connected with customers by introducing higher level segments' expenses. Additional benefits provided by activities in the company's value chain will be provided on these levels. These activities will generate the expenses that will further influence the profit achieved in the lower reporting segments. 
The market is usually defined as customers having the same need. However, it has customers that can be grouped in different ways as marketing segments. The company can target more than one segment. This is the reason why market is on higher hierarchical level than market segments. The overall financial and marketing result achieved on all targeted marketing segments will create the result for the market as a whole. Some additional benefits can be provided on this level, such as health checking of foods (for food producers) that provide general safety for customers in all marketing segments. Other products may demand fulfilling some other standards required by the law. Special offers can be activities that are generated on this level.

This leads to the next level - national markets. Tariffs, special charges, changes of product label, etc. are examples of the needed changes that influence the profit contribution achieved on an individual national market. In modern times, it is important for the management of multinational companies to control the plan vs. actual results on individual national markets on which the company operates. Reports that measure different performances, financial as well as non-financial, will show whether the strategy is implemented properly or not at individual national markets.

Brands and distribution channels as segments can be on different levels, from customer groups up to the company level. Brands can be shaped for the company itself, but can also be targeted for customer groups, market segments, markets or national markets. Depending on the customer level on which the brand is defined, the total brand will be positioned as reporting segment and as sa pecific level inside the pyramid. That is, psychological differentiation can start on the customer group level and be carried out up to the top level of the business segment, that is, for the company as whole.

It is the same with distribution channels as with brands. They can be positioned inside the hierarchy of the segments between different segment levels. The distribution can be organized separately for products, customer groups, market segments, markets, national market, strategic business unit or the company itself. Distribution activities will be the ones that create location benefit for customers and generate the expenses during this process.

Finally, how is this connected with the previously mentioned principles? Firstly, functional strategies of the strategy are covered. Products are mostly the responsibility of the production. Marketing has a responsibility from products up to the national markets. Financial function is represented with calculation of profit and assets used in each business segment. The SBU or divisions are the responsibilities of the corporate strategy since they mostly correspond to the industries chosen in the corporate strategy. Activities and benefits which activities generate will present the competitive level of the strategy in each segment level since they generate benefits that are part of the competitive advantage. Secondly, revenues are generated by sales of products and a fterwards, by selling them to the customers that the products were created for. On a higher level of the hierarchy, these customers are grouped generating the results for markets, national markets that a SBU operates in and the company as a whole.

The point is that the revenues and costs can be calculated for each segment. Due to this, contribution to profit for each segment and its responsible manager can be calculated leading to its impact to the profit of the company itself. Segment levels will show how these individual results are interconnected.

\section{Activity Based Cost Hierarchies in Segment Pyramid}

"To discuss management and at the same time neglect accounting as a basic source of information is really not possible." (Kneževic at al., 2012, p. 68) This leads to the issue of activity based costing, as a source of distributing the expenses to the proper reporting segment. The ABC has integrated procedures for compiling the list of activities for each cost object. (Kaličanin\&Knežević, 2013, p. 107) Having in mind that segment reports are nothing but groups of cost objects of the same type, it is clear that activity based costing is the main methodology behind the different segment reports. More precisely, the activity based costing has cost hierarchy for each cost object proposed in the hierarchy.

It is well known that there is a product hierarchy of costs in the activity based costing, as management accounting tool. It was created by Cooper in 1990. (Bromwich, 1997, p. 44) Cost hierarchies are presented for customers and distributors as well as for brands. (Foster and Gupta, 1994, pp. 86, 88) The more updated cost hierarchies for the product separate the support level as the third level of costs and split it into support 
of customers, channels as separate levels. Also, the overall support is broken into two levels as business support and other support. (Atkinson at all, 2007, pp. 56-62)

The segment reports are also a possible way of making a kind of unified cost hierarchy inside the activity based costing. This is due to fact that product hierarchy can be implemented on the product level, customer hierarchy on the levels from customers to national market. Also, it can be implemented on the distribution level since there is no real principal difference between distributors and buyers. However, these hierarchies are overlapping. Some activities will exist in more than one hierarchy.

First, it is obvious that one activity cannot be connected with just one segment level. If the activity is connected with customers but can be allocated by cost driver to product too, it is possible that it be present on both business segment levels. For example, if transport is performed for a couple of products to one customer, the cost of this activity can be easily allocated to that customer. Using ton/kilometre as cost driver will make possible for this expense to be also allocated to the specific product on support level of the product hierarchy considering the weight of product.

If the reports are made for a product manager or a customer manager, cost like transport should be included in individual reports for both managers. In this manner, both can see how the transport expenses influence their areas of responsibility. This will potentially make them realize the benefits of mutual cooperation in order to reduce the transport costs. For example, the production manager can search for the ways of reducing the product weight such as lighter packaging to reduce transport costs while the marketing manager will search for a lighter package that can be acceptable for the market.

It is well known that marketing and production managers will confront in the area of product variability. Marketing asks for more variation in products. If preparation of the product is included on batch level of costs, for the managers on the first segment level and later transferred to the market segment manager and his report, both managers will have their motives to make these expenses minimal. This will improve the inter-functional cooperation. It will be easier to find ways to achieve optimal organization of work between different functions on the functional level of the strategy.

Secondly, the need for some expenses to be shown on more than one level should not be confused with their natural belonging to a specific segment! If the activity is allocated to just its naturally belonging segment, the structure of cost per business segments can be determined.

The allocation of the activity expense to its "natural" business segment is easy if it is known which cost object they were naturally created for. Expenses of transport activities are naturally connected with distribution. Expenses of servicing the customers are naturally connected with the customer, customer group or market segment. Tariffs are connected with the national market, etc.

Similarly, the expenses of general administration or location of the factory etc. should be allocated on the division/strategic business unit level or to the company. These will probably be supporting activities in the value chain. Due to this, all these expenses should be allocated to one of these segments originally. When needed, they will be shown in more than one of the segment reports for managers responsible.

Having this in mind, the structure of cost per business segment can be created. It will be possible to know how much expenses each type of cost objects grouped into the business segments creates. It will be possible to track the expenses per each segment level and its share in the total expense value of the company as a newly defined cost structure. To say once again, it is possible to know how much expenses cost objects grouped at each segment level caused. 
Having all above in mind, it can be claimed that segment reports can now be logically structured. Due to this, the segment reports will be interconnected logically. The managers responsible for each segment will now see where the revenues and expenses are overlapping and can work together to optimize their value. Also, it can be seen how the result of one business segment influences the results of the expenses above and the result of the entire company. Ae different from usual structure of expenses can be defined leading to the new potential management insights.

There are potential benefits in forensic accounting and responsibility accounting as well. With a better understanding of the connection between different reports, the potential issues concerning fraud and responsibilities can be more easily identified. Interdependences can be established between different areas of management responsibilities as well as strict responsibilities of each manager. Due to this, the issues indentified within forensic accounting can also be directly connected with a responsible manager.

\section{REFERENCES}

[1] Atkinson, A. A., Kaplan, R., Matsumura, E. M., Young, S. M. (2007). Management Accounting, Pearson Prentice Hall, Upper Saddle River, New Jersey

[2] Barret, T. F. (1980). Modular database system. International Journal of Physical Distribution and Material Management, 12, pp. 135-146

[3] Bromwich, M. (1997). Accounting for Overheads - Critique and Reforms, CIMA, Uppsala Stockholm

[4] Foster, G., Gupta, M. Marketing, (1994). Cost Management and Management Accounting. Journal of Management Accounting, Fall 1994, 43-77 in Wilson, R. (2001). Marketing Controllership, Dartmouth Publishing Company, Aldershot, p. 88

[5] Grant, R. (1992). Contemporary Strategy Analysis - Concepts, Techniques, Applications, Blackwell Business, Cambridge Massachusetts

[6] Kaličanin, Dj., Knežević, V. (2013). Activity-Based Costing as an Information Basis for an Efficient Strategic Management Processs, Economics Annals, April - June, pp. 95-119

[7] Knežević, S., Stanković, A., Tepavac, R. (2012). Accounting Information System as a Platform for Business and Financial Decision-Making in the Company, Management Journal of Theory and Practice Management, no. 65 , pp. 63-69

[8] Kotler, P. (1972). Marketing Management, Pearson Prentice Hall Inc, Englewood, New York

[9] Kotler, P., Keller, L. K., Brady, M., Goodman, M., Hansen, T., (2009). Marketing Management, Pearson Prentice Hall, Harlow, England

[10] Porter, M. (1990). The Competitive Advantage of Nations, The Macmillan Press Ltd., London

[11] Ward, K., (1993). Strategic Management Accounting, Butterworth-Heinemann Ltd, CIMA, Oxford

[12] Wilson, M. S. R., Gilligan, C. (2005). Strategic Marketing Management, Elsevier, Amsterdam

[13] Wilson, R. (1999). Accounting for Marketing, International Thomson Business Press, London

Receieved: December 2014. Accepted: June 2015.

\section{|||||||||||||||||||||||||||||||| $\mid$ soouthounator}

\section{Danilo Dorović}

Tedex doo

The author has written a number of articles considering the construction of management reports. He has a wide experience in business models, controlling, management and financial consulting, management reporting for different clients.

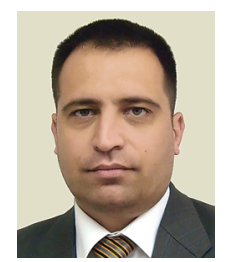

